\title{
Comentario
}

\section{La calidad en la formación bibliotecológica}

工 a formación de recursos humanos para las bibliotecas imsiderar; como son el conjunto de conocimientos que se pretende dar a los estudiantes, la formación y nivel de los docentes y alumnos, la infraestructura tecnológica, la infraestructura administrativa, la biblioteca, etcétera, elementos que siempre se han cuidado para brindar una formación bibliotecológica adecuada y ajustada con el perfil de egreso ¿Porqué cuestionarse entonces la calidad de la formación profesional del bibliotecólogo en la sociedad de la información, en la que se hace cada vez más evidente la necesidad de estos profesionales? El hecho es que la falta de credibilidad sobre la calidad de los profesionales egresados de tantas escuelas privadas y públicas, convoca la necesidad de contar con sistemas sociales de acreditación que garanticen la calidad de formación de los profesionales de todas las áreas.

En la sociedad de la información y en el contexto de la globalización, son tres los fenómenos que obligan al bibliotecólogo y a las instituciones que los forman a reflexionar sobre la calidad de la formación profesional.

En primer lugar la formación ha dejado de ser un proceso con principio y fin, ahora la sociedad exige una formación mediante la cual se actualicen los conocimientos y habilidades permanentemente para lograr un mejor desempeño de las actividades productivas y demostrarle a la sociedad que los bibliotecarios cuentan con una mejor preparación y mayor conocimiento.

En segundo lugar el empleo ya no suele ser permanente ni se tiene seguridad de tenerlo para toda la vida, y esta incertidumbre laboral lleva a los profesionales a buscar los mecanismos que garanticen y muestren su calidad para permanecer activos en el mercado. 
El tercer fenómeno es que el desarrollo tecnológico y de las telecomunicaciones han transformado sustancialmente la cultura educativa y laboral, y obligado a los profesionales a mantenerse actualizados en el uso de estas herramientas.

De esta forma el bibliotecólogo debe demostrar, a nivel nacional e internacional, su nivel de competitividad para seguir teniendo vigencia en el mercado profesional, lo cual indica que hay que seguir formándolos para ser competitivos y fomentar o desarrollar en ellos características de liderazgo y capacidad para adelantarse a los problemas y para generar productos y servicios, así como para convencer a la sociedad acerca de los beneficios de la profesión y la vinculación estrecha que ésta tien con la generación de conocimiento y con el desarrollo social, cultural y científico de la sociedad.

El medio más adecuado para dar a conocer esta calidad en la formación de los bibliotecólogos es la acreditación y la certificación profesional; la primera para evaluar los programas de formación bibliotecológica y dar a conocer el nivel de calidad con que se están formando los recursos humanos en las diversas instituciones educativas; la segunda para certificar al profesional en lo específico, certificación que se puede dar a partir de dos enfoques: a) la certificación profesional que avala un nivel académico y que facilita a las universidades el proceso de evaluación para obtener el nivel profesional; y b) la certificación del ejercicio profesional que avala el nivel de calidad con que se ejerce una profesión, mediante la evaluación de las personas que están en ejercicio profesional y en una constante actualización profesional.

En estos procesos de acreditación y certificación, los colegios de profesionales juegan un papel trascendental, ya que como instituciones sociales que organizan a un gremio profesional son los responsables de generar los sistemas de evaluación con indicadores y parámetros internacionales que muestren a esta sociedad de la información la calidad que tiene la formación de los recursos humanos para las bibliotecas.

\section{Lina Escalona Ríos}

